\title{
Assessment of subjective outcomes in women after treatment of lower urinary tract symptoms
}

\author{
Shruthi Shivashankar*, N. V. Manjula \\ Department of Obstetrics and Gynaecology, Ramaiah Medical College, Bangalore, Karnataka, India
}

Received: 16 July 2021

Revised: 08 August 2021

Accepted: 09 August 2021

\section{*Correspondence:}

Dr. Shruthi Shivashankar,

E-mail: hita.shruthi@gmail.com

Copyright: ( ) the author(s), publisher and licensee Medip Academy. This is an open-access article distributed under the terms of the Creative Commons Attribution Non-Commercial License, which permits unrestricted non-commercial use, distribution, and reproduction in any medium, provided the original work is properly cited.

\section{ABSTRACT}

Background: Lower urinary tract symptoms (LUTS) are the most common symptoms in women at all age groups worldwide. Their overall prevalence among women is $67 \%$, and incidence increases with age. To assess the impact of LUTS comprehensively, it is therefore necessary to measure both the level of an individual's symptoms and the extent to which they impair their life. This is particularly important when making a decision as to whether an individual is likely to require or benefit from treatment, and in evaluating the effectiveness of such treatment. Aim and objectives were to assess the subjective outcomes in women following treatment of lower urinary tract symptoms using King's health questionnaire (KHQ).

Methods: This study was carried out in 106 women presenting with LUTS at Ramaiah Medical College and Hospital as per the inclusion and exclusion criteria from November 2017 to June 2019. KHQ was used to assess subjective outcomes pre-treatment and 3 months post-treatment. Statistical analysis was done using the statistical software namely IBM statistical package for the social sciences (SPSS) statistics version 22.

Results: There was significant improvement in all the domains of KHQ indicating that patients had a better quality of life (QoL) post treatment. The mean total KHQ score decreased from a maximum of 40.14 at the pre-treatment time point to a minimum of 12.25 at the post treatment time point. This change was statistically significant. $90.6 \%$ of the participants had subjective improvement following treatment of LUTS. $9.4 \%$ of the participants reported no improvement in quality of life QoL following treatment of LUTS.

Conclusions: This study shows the value of KHQ as an evaluation tool to determine the subjective outcome in women following treatment of LUTS. There was significant improvement in all the domains of KHQ between the two time points in our study indicating a better QoL following the treatment given with subjective improvement of $90.6 \%$.

Keywords: King's health questionnaire, LUTS, Quality of life, Subjective outcomes, Incontinence

\section{INTRODUCTION}

Lower urinary tract symptoms (LUTS) are the most common symptoms in women at all age groups worldwide. Their overall prevalence among women is 67\%, and incidence increases with age. ${ }^{1,2}$ LUTS are the subjective indicators of a disease or a change in conditions as perceived by the patients, carer or partners and may lead her to seek help from health care professionals. In general, lower urinary tract symptoms alone cannot be used to make a definitive diagnosis but however LUTS may indicate underlying lower urinary tract pathologies. ${ }^{3}$

To assess the impact of lower urinary tract symptoms comprehensively, it is therefore necessary to measure both the level of an individual's symptoms and the extent to which they impair their life. This is particularly important when making a decision as to whether an individual is likely to require or benefit from treatment, and in evaluating the effectiveness of such treatment. 
The Kings health questionnaire (KHQ) is a disease specific quality of life tool used to obtain a standardised subjective and symptomatic measure of the effect of treatments, whether conservative, medical and surgical, on urinary tract disorders. ${ }^{4}$

In this study we use the KHQ to assess the subjective outcomes in women presenting with LUTS and following its treatment.

\section{Aims and objectives}

Aims and objectives were to assess the subjective outcomes in women following treatment of lower urinary tract symptoms using KHQ.

\section{METHODS}

This study was carried out in 106 women presenting with LUTS at Ramaiah Medical College and Hospital from November 2017 to June 2019.

The inclusion criteria were women of age group of 18-65 years and those presenting with LUTS. The exclusion criteria included women with diabetes, pregnant women, women with neurological disease and those with urinary tract infection (UTI) based on urine analysis.

\section{Methods of data collection}

Ethical clearance was obtained from institutional ethics committee for this study (SS-1/EC/039/2017 dated 02/11/2017). A written informed consent was taken from all the study subjects.

Patient was asked to answer a questionnaire - KHQ, pertaining to lower urinary tract symptoms after obtaining a brief menstrual and obstetric history and thorough detailed clinical examination. Age of the woman was recorded in completed years.

Patients were evaluated further by urine analysis. Urodynamic studies were done only in selected cases where diagnosis could not be made based on history and clinical examination. Treatment was provided according the diagnosis made. Patients diagnosed to have urge incontinence/overactive bladder were treated with anticholinergic drugs. Patients with stress incontinence were managed either conservatively with pelvic floor exercises or surgically by sling procedures depending on age, severity and duration of symptoms. Patients with fistulas were treated by surgical repair. Patients with stricture urethra were managed conservatively by urethral dilation and those with pelvic organ prolapse were managed either surgically or conservatively.

3 months post treatment, patients were followed up and the same questionnaire was used to evaluate and compare subjective outcomes.

\section{Statistical analysis}

All the quantitative parameters like age, body mass index (BMI), KHQ scores was presented using descriptive statistics such as mean and standard deviation or median and range.

All the qualitative parameters such as education, parity, socioeconomic status, occupation, subjective outcome was presented using frequency and percentages.

Descriptive statistics were used and the univariate analysis was made using a Chi-squared test for categorical data.

Non-parametric tests such as Fisher's exact test, Kruskal Wallis test, Spearman correlation, Wilcoxon test were used to make group comparisons where data was not uniformly distributed. A p value $<0.05$ was considered significant.

Stuart-Maxwell test was used to assess the change in a variable between the two time points.

\section{Statistical software}

The statistical software namely IBM statistical package for the social sciences (SPSS) statistics version 22 was used for the analysis of the data and Microsoft word and excel have been used to generate graphs and tables.

\section{RESULTS}

A total of 106 women presenting with LUTS were included in the study after fulfilling the inclusion and exclusion criteria.

The most common symptom that patients presented with was urinary incontinence $(46.2 \%)$, followed by urgency $(33.0 \%)$ and frequency $(27.4 \%)$ (Table 1$)$.

Table 1: Summary of LUTS.

\begin{tabular}{|ll|}
\hline Symptoms & $\mathbf{N}(\%)$ \\
\hline Frequency & $29(27.4)$ \\
\hline Urgency & $35(33.0)$ \\
\hline Nocturia & $14(13.2)$ \\
\hline Urinary incontinence & $49(46.2)$ \\
\hline Bedwetting & $1(0.9)$ \\
\hline Bladder pain & $2(1.9)$ \\
\hline Hesitancy & $14(13.2)$ \\
\hline Poor stream & $13(12.3)$ \\
\hline Dysuria & $1(0.9)$ \\
\hline Post micturition dribble & $1(0.9)$ \\
\hline Incomplete voiding & $23(21.7)$ \\
\hline Mass per vagina & $28(26.4)$ \\
\hline
\end{tabular}

$49.1 \%$ of the participants belonged to age group of 50-65 Years and $31.1 \%$ of the participants belonged to age group of 40-49 years (Table 2). 
Table 2: Demographic details of the participants $(n=106)$.

\begin{tabular}{|c|c|c|}
\hline Parameter & Number & Percentage \\
\hline \multicolumn{3}{|l|}{ Age in years } \\
\hline $18-29$ & 4 & 3.8 \\
\hline $30-39$ & 17 & 16.0 \\
\hline $40-49$ & 33 & 31.1 \\
\hline $50-65$ & 52 & 49.1 \\
\hline \multicolumn{3}{|l|}{$\mathrm{BMI}$ in $\mathrm{kg} / \mathrm{m}^{2}$} \\
\hline$\leq 24.9$ & 37 & 34.9 \\
\hline $25.0-29.9$ & 48 & 45.3 \\
\hline$>30.0$ & 21 & 19.8 \\
\hline \multicolumn{3}{|l|}{ Menstrual status } \\
\hline $\begin{array}{l}\text { Reproductive (regular } \\
\text { cycles) } 45\end{array}$ & 36 & 34.0 \\
\hline $\begin{array}{l}\text { Reproductive (irregular } \\
\text { cycles) }\end{array}$ & 4 & 3.8 \\
\hline Perimenopausal & 6 & 5.7 \\
\hline Postmenopausal & 45 & 42.5 \\
\hline Post-hysterectomy & 15 & 14.2 \\
\hline \multicolumn{3}{|l|}{ Socio economic status } \\
\hline Upper & 2 & 1.9 \\
\hline Upper middle & 21 & 19.8 \\
\hline Lower middle & 62 & 58.5 \\
\hline Upper lower & 20 & 18.9 \\
\hline Lower & 1 & 0.9 \\
\hline \multicolumn{3}{|l|}{ Parity } \\
\hline$\leq 2$ & 68 & 64.2 \\
\hline$>2$ & 38 & 35.8 \\
\hline
\end{tabular}

$41.5 \%$ of the participants were postmenopausal and $37.8 \%$ of the participants belonged to reproductive age group (Table 2).

$58.5 \%$ of the participants belonged to lower middle socio economic status according to modified Kuppuswamy classification. ${ }^{5} 19.8 \%$ of the participants belonged to upper middle socio economic status and $18.9 \%$ of the participants were of upper lower socio economic status (Table 2).

$34.9 \%$ of the participants had BMI less than $24.9 \mathrm{~kg} / \mathrm{m}^{2}$. $45.3 \%$ of the participants had BMI of $25.0-29.9 \mathrm{~kg} / \mathrm{m}^{2}$. $19.8 \%$ of the participants had BMI $>30.0 \mathrm{~kg} / \mathrm{m}^{2}$ (Table 2).

$64.2 \%$ of the participants had parity less than or equal to 2 . $35.8 \%$ of the participants had parity $>2$ (Table 2 ).

$14.2 \%$ of the participants were diagnosed to have SUI. $33.0 \%$ of the participants were diagnosed to have (urge urinary incontinence/overactive bladder (UUI/OAB).
$23.6 \%$ of the participants were diagnosed with POP. $8.5 \%$ of the participants were diagnosed with urinary incontinence with pelvic organ prolapse (UI and POP) (Table 3).

Table 3: Distribution of the participants in terms of primary diagnosis $(n=106)$.

\begin{tabular}{|lll|}
\hline Primary diagnosis & Frequency & Percentage \\
\hline SUI & 15 & 14.2 \\
\hline MUI & 7 & 6.6 \\
\hline UUI/OAB & 35 & 33.0 \\
\hline VVF & 4 & 3.8 \\
\hline Urethral stricture & 9 & 8.5 \\
\hline POP & 25 & 23.6 \\
\hline UI+POP & 9 & 8.5 \\
\hline Urethral diverticulum & 2 & 1.9 \\
\hline Total & 106 & 100.0 \\
\hline
\end{tabular}

$49.1 \%$ of the participants received pharmacological/ conservative treatment. $44.3 \%$ of the participants received surgical treatment and remaining $6.6 \%$ of the participants had received surgical and pharmacological/conservative treatment (Figure 1).

All patients with VVF and urethral diverticulum were managed surgically. Patients with urethral stricture were managed conservatively with urethral dilatation or surgically by urethroplasty. All patients with UUI/OAB were managed with anticholinergic drugs. Treatment for SUI included surgical management by TOT and conservative management by PFMT (Figure 2).

The mean total KHQ score decreased from a maximum of 40.14 at the pre-treatment time point to a minimum of 12.25 at the post-treatment time point. This change was statistically significant (Wilcoxon test: $\mathrm{V}=5565.0$, $\mathrm{p} \leq 0.001$ ) (Table 4).

The mean (SD) of change in total KHQ score was 27.89 (20.51). The median (IQR) of change in total KHQ score was 20.00 (22.00). The change in total KHQ score ranged from 0-90 (Table 5).

$90.6 \%$ of the participants had subjective improvement following treatment of LUTS. 9.4\% of the participants reported no improvement in QoL following treatment of LUTS (Table 6).

There was a significant difference between the 8 groups in terms of change in total KHQ score $\left(\mathrm{X}^{2}=22.558, \mathrm{p}=0.002\right)$, with the median change in total KHQ score being highest in the primary diagnosis: VVF group (Table 7).

There was no significant difference between the various primary diagnosis groups in terms of distribution of subjective outcome $\left(\mathrm{X}^{2}=3.880, \mathrm{p}=0.923\right)$ (Table 8$)$. 


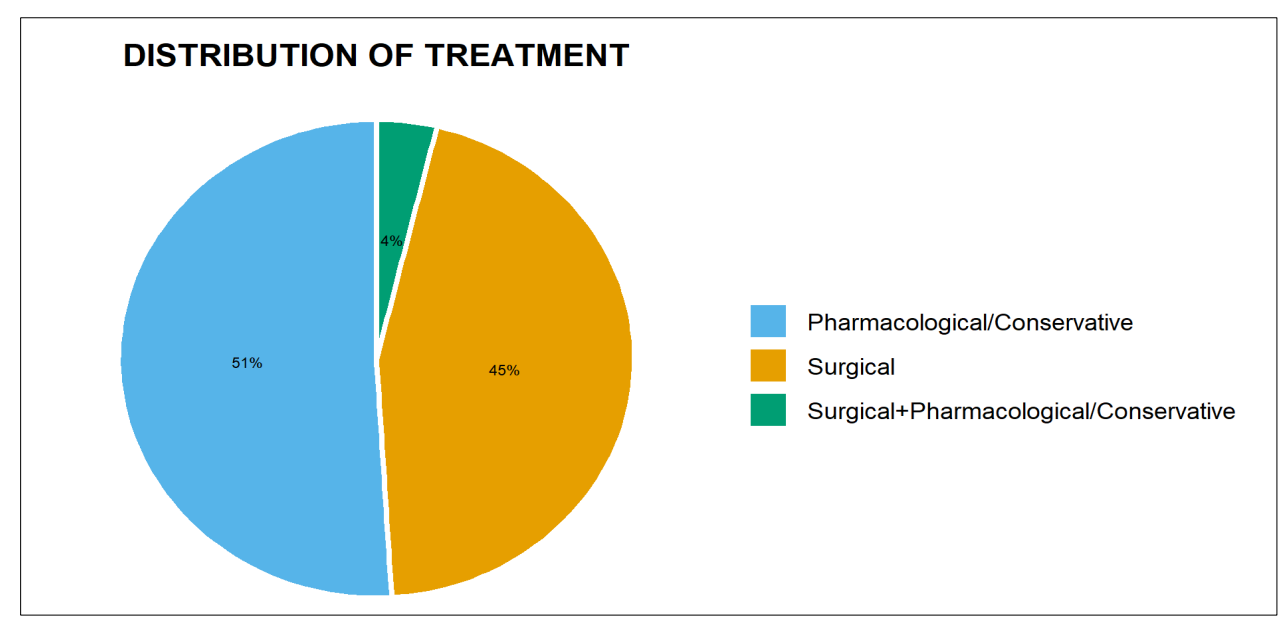

Figure 1: Distribution of treatment among study participants.

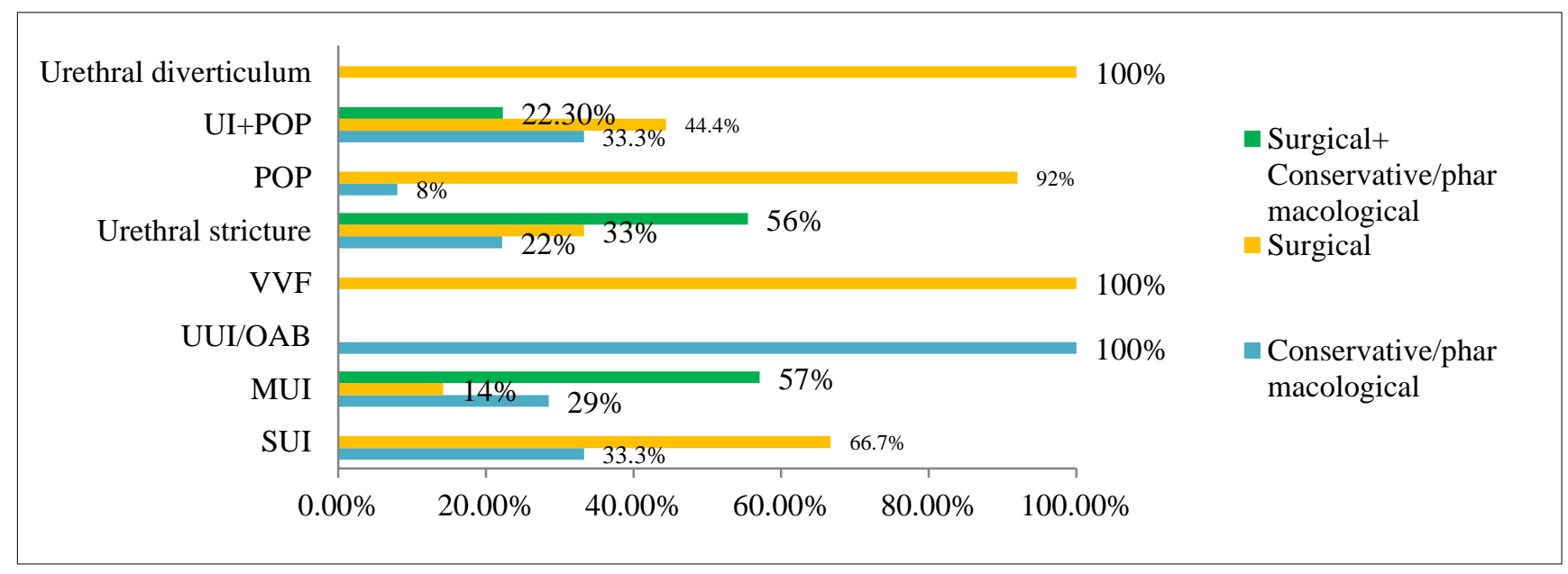

Figure 2: Treatment given for the various primary diagnosis.

Table 4: Assessment of change in total KHQ score over time (n=106).

\begin{tabular}{|c|c|c|c|c|c|}
\hline \multirow{2}{*}{ Timepoint } & \multicolumn{3}{|c|}{ Total KHQ score } & \multicolumn{2}{|c|}{ Wilcoxon test } \\
\hline & Mean (SD) & Median (IQR) & Range & $\mathbf{V}$ & $P$ value \\
\hline Pre treatment & $40.14(22.58)$ & $36.00(36.00)$ & $12.00-97.00$ & \multirow{4}{*}{5565.0} & \multirow{4}{*}{$<0.001$} \\
\hline Post treatment & $12.25(13.15)$ & $8.00(11.00)$ & $0.00-71.00$ & & \\
\hline Absolute change & $27.89(20.51)$ & $20.00(22.00)$ & $0.00-90.00$ & & \\
\hline Percent change & $68.6(23.3)$ & $72.8(35.7)$ & $100-0$ & & \\
\hline
\end{tabular}

Table 5: Distribution of the participants in terms of change in total KHQ score (n=106).

\begin{tabular}{|ll|}
\hline Change in total KHQ score & Range \\
\hline Mean (SD) & $27.89(20.51)$ \\
\hline Median (IQR) & $20(22)$ \\
\hline Range & $0-90$ \\
\hline
\end{tabular}

Table 6: Subjective outcome in our study $(n=106)$.

\begin{tabular}{|lll|}
\hline Subjective outcome & Frequency & Percentage \\
\hline Improved & 96 & 90.6 \\
\hline No change & 10 & 9.4 \\
\hline Total & 106 & 100.0 \\
\hline
\end{tabular}


Table 7: Comparison of the primary diagnosis and change in total KHQ score $(n=106)$.

\begin{tabular}{|c|c|c|c|c|c|c|c|c|c|c|}
\hline \multirow{2}{*}{$\begin{array}{l}\text { Change } \\
\text { in total } \\
\text { KHQ } \\
\text { score }\end{array}$} & \multicolumn{8}{|c|}{ Primary diagnosis } & \multicolumn{2}{|c|}{$\begin{array}{l}\text { Kruskal } \\
\text { Wallis test }\end{array}$} \\
\hline & SUI & MUI & $\begin{array}{l}\text { UUI/ } \\
\text { OAB }\end{array}$ & VVF & $\begin{array}{l}\text { Urethral } \\
\text { Stricture }\end{array}$ & POP & UI+POP & $\begin{array}{l}\text { Urethral } \\
\text { diverticu } \\
\text {-lum }\end{array}$ & $\mathrm{X}^{2}$ & $\begin{array}{l}P \\
\text { value }\end{array}$ \\
\hline $\begin{array}{l}\text { Mean } \\
\text { (SD) }\end{array}$ & $\begin{array}{l}28.20 \\
(19.81)\end{array}$ & $\begin{array}{l}49.14 \\
(26.95)\end{array}$ & $\begin{array}{l}24.09 \\
(13.31)\end{array}$ & $\begin{array}{l}75.75 \\
(13.82)\end{array}$ & $\begin{array}{l}31.33 \\
(21.71)\end{array}$ & $\begin{array}{l}20.92 \\
(15.76)\end{array}$ & $\begin{array}{l}17.78 \\
(14.90)\end{array}$ & $\begin{array}{l}39.00 \\
(29.70)\end{array}$ & \multirow{3}{*}{$\begin{array}{l}22.5 \\
58\end{array}$} & \multirow{3}{*}{0.002} \\
\hline $\begin{array}{l}\text { Median } \\
\text { (IQR) }\end{array}$ & $\begin{array}{l}31 \\
(22.5)\end{array}$ & $55(47)$ & $22(22.5)$ & $\begin{array}{l}75.5 \\
(21.25)\end{array}$ & $29(21)$ & $15(11)$ & $13(3)$ & $39(21)$ & & \\
\hline Range & $0-71$ & $16-79$ & $4-54$ & $62-90$ & $13-71$ & $4-73$ & $7-56$ & $18-60$ & & \\
\hline
\end{tabular}

Table 8: Association between primary diagnosis and subjective outcome $(n=106)$.

\begin{tabular}{|c|c|c|c|c|c|c|c|c|c|c|c|}
\hline \multirow{2}{*}{$\begin{array}{l}\text { Subjective } \\
\text { outcome }\end{array}$} & \multicolumn{9}{|c|}{ Primary diagnosis } & \multicolumn{2}{|c|}{$\begin{array}{l}\text { Fisher's } \\
\text { exact test }\end{array}$} \\
\hline & SUI & MUI & $\begin{array}{l}\text { UUI/ } \\
\text { OAB }\end{array}$ & VVF & $\begin{array}{l}\text { Urethral } \\
\text { stricture }\end{array}$ & POP & $\begin{array}{l}\text { UI+ } \\
\text { POP }\end{array}$ & $\begin{array}{l}\text { Urethral } \\
\text { diverticulum }\end{array}$ & Total & $\mathbf{X}^{2}$ & $\begin{array}{l}P \\
\text { value }\end{array}$ \\
\hline Improved & $\begin{array}{l}14 \\
(93.3)\end{array}$ & $\begin{array}{l}7 \\
(100 . \\
0)\end{array}$ & $\begin{array}{l}31 \\
(88.6)\end{array}$ & $\begin{array}{l}4 \\
(100 . \\
0)\end{array}$ & $9(100.0)$ & $\begin{array}{l}21 \\
(84.0)\end{array}$ & $\begin{array}{l}8 \\
(88.9)\end{array}$ & $2(100.0)$ & $\begin{array}{l}96 \\
(90.6)\end{array}$ & \multirow{3}{*}{$\begin{array}{l}3.88 \\
0\end{array}$} & \multirow{3}{*}{0.923} \\
\hline No change & $\begin{array}{l}1 \\
(6.7)\end{array}$ & $\begin{array}{l}0 \\
(0.0)\end{array}$ & $\begin{array}{l}4 \\
(11.4)\end{array}$ & $\begin{array}{l}0 \\
(0.0)\end{array}$ & $0(0.0)$ & $\begin{array}{l}4 \\
(16.0)\end{array}$ & $\begin{array}{l}1 \\
(11.1)\end{array}$ & $0(0.0)$ & $10(9.4)$ & & \\
\hline Total & $\begin{array}{l}15 \\
(100 . \\
0)\end{array}$ & $\begin{array}{l}7 \\
(100 . \\
0)\end{array}$ & $\begin{array}{l}35 \\
(100 . \\
0)\end{array}$ & $\begin{array}{l}4 \\
(100 . \\
0)\end{array}$ & $9(100.0)$ & $\begin{array}{l}25 \\
(100 . \\
0)\end{array}$ & $\begin{array}{l}9 \\
(100 . \\
0)\end{array}$ & $2(100.0)$ & $\begin{array}{l}106 \\
(100.0)\end{array}$ & & \\
\hline
\end{tabular}

\section{DISCUSSION}

Precise assessment of LUTS using validated tools helps in obtaining better outcome in patient management.

In our study, $49.1 \%$ of the participants belonged to age group of 50-65 years and $31.1 \%$ of the participants belonged to age group of 40-49 years. The mean (SD) age in years was 49.22 (10.59). Stewart et al reported mean age of women presenting with LUTS to be 54.2 years. $^{6}$

$64.2 \%$ of the participants in our study had parity less than or equal to 2 and $35.8 \%$ of the participants had parity $>2$. Whereas Komeilifar et al reported greater prevalence of LUTS in women with parity $>2(55 \%) .^{7}$ In our study, $34.9 \%$ of the participants had BMI less than $24.9 \mathrm{~kg} / \mathrm{m}^{2}$. $45.3 \%$ of the participants had BMI of $25.0-29.9 \mathrm{~kg} / \mathrm{m}^{2}$. $19.8 \%$ of the participants had BMI $>30.0 \mathrm{~kg} / \mathrm{m}^{2}$ indicating majority of women having BMI classified as overweight. The same finding was noted by Komeilifar R et al where majority patients were overweight. ${ }^{7}$

Studies by Fatima et al and Reilly et al showed significant improvement in KHQ questionnaire scores following treatment of LUTS. ${ }^{8,9}$ In our study, the mean total KHQ score decreased from a maximum of 40.14 at the pretreatment time point to a minimum of 12.25 at the post treatment time point. This change was statistically significant indicating subjective improvement following treatment.
In the present study, $90.6 \%$ of the participants had subjective improvement following treatment of LUTS. 9.4\% of the participants reported no improvement in QoL following treatment of LUTS. A Japanese study in 161 patients with UI operated on for this condition used the incontinence impact questionnaire-7 (IIQ-7) and found that after 2 years, all domains had significantly improved and $88 \%$ of patients were satisfied with the outcome of the surgical procedure. ${ }^{10}$ Another study by Šimunić et al also evaluated 1612 patients with urogenital complaint women and found a subjective improvement of $85.5 \%$ following treatment. ${ }^{11}$

This qualitative inquiry of patients' perspectives on the outcomes of seeking medical care for the symptom-based condition of LUTS has several implications. The value patients place on partial symptom relief and the patientprovider relationship broadens the criteria for quality of care beyond providing a cure.

Limitations of this study include small enrollment numbers and visit numbers overall, which limited our ability to discriminate differences in treatment success. Although shorter observation intervals suggest that incontinence status is dynamic with high remission over longer observation, incontinence has a propensity to recur. Generally majority of the patients in our study improved between our two time points. But long term follow up is needed to know if patients had recurrent LUTS and required further evaluation and treatment. The effect of urodynamic studies on the subjective outcome could not 
be assessed in our study as it was not uniformly performed in all patients. Urodynamic studies were done only in patients where there was a dilemma in diagnosis, mostly in cases of $\mathrm{OAB}$.

During a woman's lifetime various health conditions can challenge bladder function. LUTS can worsen or improve and the desire for management can wax and wane. Management should begin by assessing the patient's willingness to engage in treatment, determining the level of treatment desired and discussing current evidence and recommendations for specific forms of treatment, including benefits, alternatives, risks and complications. ${ }^{12}$ Furthermore, assessment of quality of life has become an integral part of determining the effect of LUTS on the individual and assessing the benefit of treatments.

\section{CONCLUSION}

This study shows the value of KHQ as an evaluation tool to determine the subjective outcome in women following treatment of LUTS. There was significant improvement in all the domains of KHQ between the two time points in our study indicating a better QoL following the treatment given with subjective improvement of $90.6 \%$. Thus subjective outcome assessed using standard questionnaire such as KHQ can help evaluate treatment given and thus help improve quality of life in women suffering with LUTS.

Funding: No funding sources

Conflict of interest: None declared

Ethical approval: The study was approved by the Institutional Ethics Committee

\section{REFERENCES}

1. Bilgic D, Beji NK. Lower urinary tract symptoms in women and quality of life. Int J Urol Nurs. 2010;4:97105.

2. Bradway C, Coyne KS, Irwin D. Lower urinary tract symptoms in women-a common but neglected problem. J Am Acad Nurse Pract. 2008;20(6):311-8.

3. Abrams P, Cardozo L, Fall M, Griffiths D, Rosier P, Ulmsten, van Kerrebroeck P, Victor A, Wein A. The standardisation of terminology of lower urinary tract function: Report from the standardisation subcommittee of the International Continence Society. Neurourol Urodyn. 2002;21:167-78.
4. Hebbar S, Pandey H, Chawla A. Understanding King's Health Questionnaire (KHQ) in assessment of female urinary incontinence. Int J Res Med Sci. 2017;3(3):531-8.

5. Shaikh Z, Pathak R. Revised Kuppuswamy and B G Prasad socio-economic scales for 2016. Int J Comm Med Public Health. 2017;4(4):997-9.

6. Stewart WF, Van Rooyen JB, Cundiff GW, Abrams P, Herzog AR, Corey R, et al. Prevalence and burden of overactive bladder in the United States. World J Urol. 2003;20:327-36.

7. Komeilifar R, Javadifar N, Afshari P, Haghighizade $\mathrm{MH}$, Honarmandpour A. The prevalence, subtypes and obstetric risk factors of urinary incontinence in reproductive age women referred to community health care centers of Dezful, Iran-2015. Int J Comm Based Nurs Midwifery. 2017;5(3):275.

8. Fitz FF, Costa TF, Yamamoto DM, Resende AP, Stüpp L, Sartori MG, Girão MJ, Castro RA. Impact of pelvic floor muscle training on the quality of life in women with urinary incontinence. Revista da Associação Médica Brasileira (English Edition). 2012;58(2):155-9.

9. OReilly B, OSullivan O, Siddiqui K, Keane D, Skehan M. Change in quality of life scores in incontinence patients following an intervention of external electrical stimulation as determined by the Kings Health Questionnaire. Continence Foundation of Ireland, Annual Study Day. 2016.

10. Tomoe H, Kondo A, Takei M, Nakata M. Quality of life assessments in women operated on by tension-free vaginal tape (TVT). Int Urogynecol J Pelvic Floor Dysfunct. 2005;16:114-8.

11. Šimunić V, Banović I, Ciglar S, Jeren L, Pavičić Baldani D, Šprem M. Local estrogen treatment in patients with urogenital symptoms. Int J Gynecol Obstet. 2003;82(2):187-97.

12. Aoki Y, Brown HW, Brubaker L, Cornu JN, Daly JO, Cartwright R. Urinary incontinence in women. Nat Rev Dis Primers. 2017;3:17042.

Cite this article as: Shivashankar S, Manjula NV. Assessment of subjective outcomes in women after treatment of lower urinary tract symptoms. Int $\mathrm{J}$ Reprod Contracept Obstet Gynecol 2021;10:3401-6. 